AJIT SHAH

\title{
The 'Count Me In' psychiatric in-patient census for 2007 and the elderly: evidence of improvement or cause for concern?
}

\section{SUMMARY}

The recently published Count Me In 2007 census specifically reported age-standardised admission rates for individuals aged over 65 years from different Black and minority ethnic groups. The standardised admission ratio was higher in the White Irish, other White, White and Black
Caribbean, other Asian, Black Caribbean, Black African and other Black ethnic groups; and lower in the White British and Chinese ethnic groups. As this census was undertaken on a single day for all psychiatric in-patients, it measured bed occupancy rather than admission rates and so it was actually referring to standardised bed occupancy ratios. Bed occupancy is a function of admission rates and length of stay. This editorial critically explores factors (including those related to institutional racism) that may affect both admission rates and length of stay, and ultimately bed occupancy, of Black and minority ethnic elders.

\section{In-patient census findings in 2005-2007}

The 'Count Me In' 1-day censuses of all psychiatric in-patients in England and Wales for 2005 and 2006 failed to specifically report findings on those aged 65 years and over. ${ }^{1}$ This was despite a third of the psychiatric in-patients being over the age of 65 years, and the age of 65 years usually being the cut-off age for entry into old age psychiatry services. However, the recently published findings from the 2007 'Count Me In' census specifically reported age-standardised admission rates for people from different Black and minority ethnic groups over the age of 65 years. ${ }^{2}$ Still, more detailed analyses, including those for detained patients, were not conducted because the number of Black and minority ethnic elders within individual ethnic minority groups was small.

The 2007 census of 31187 patients from mental health wards in 257 National Health Service (NHS) and independent healthcare organisations included 9715 (31\%) in-patients over the age of 65 years. The standardised admission ratio, with the total elderly population of England and Wales as the standard population, for those aged 65 years and older from different ethnic groups was higher in the White Irish $(n=133)$, other White $(n=284)$, White and Black Caribbean $(n=268)$, other Asian $(n=168)$, Black Caribbean $(n=366)$, Black African $(n=291)$ and other Black $(n=434)$ groups; and lower in the White British $(n=94)$ and Chinese $(n=43)$ groups. There was no difference between the standard population and the White and Black African, White and Asian,
Indian, Pakistani, and Bangladeshi groups. These findings are broadly similar to those for all age groups combined, and the latter findings were similar to those observed in the 2005 and 2006 censuses. $1^{1}$

\section{Are higher admission rates in Black and minority ethnic groups caused by institutional racism?}

It has been powerfully argued that higher admission rates in Black Caribbean, Black African, and White and Black mixed Caribbean groups of all ages combined could be attributed to institutional racism. ${ }^{3}$ However, some have disagreed with this reasoning because they felt it had not been scientifically substantiated. Other explanations were offered, for example higher rates of mental illness in some Black and minority ethnic groups. ${ }^{4,5}$ Theoretically, similar explanations could be applied to the standardised admission ratios for Black and minority ethnic elders, given that the findings from the current census were similar to those for all age groups combined. However, alternative explanations which may partly be related to institutional racism also require careful examination focusing on determinants of admission, length of stay and bed occupancy.

\section{What did the 2007 Count Me In census really measure?}

The census was undertaken on a single day for all psychiatric in-patients and as such it did not measure 


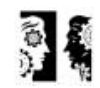

editorial admission rates - it measured bed occupancy. Despite the report referring to admission rates and standardised admission ratios, it is actually referring to bed occupancy rates and standardised bed occupancy ratios because data on all in-patients (and not admissions) were collected on the census day. Moreover, bed occupancy is a function of admission rates and length of stay; it will be higher if the admission rates are higher and/or the length of stay is longer.

\section{Black and minority ethnic elders' admission rates}

Several factors may influence admission rates among Black and minority ethnic elders. First, the prevalence of mental illness may be higher among this group than in the indigenous (White British) population. The prevalence of dementia was higher in Black Caribbean and Black African elders in Liverpool, and it was particularly high in those lacking fluency in English, ${ }^{6}$ a factor which may in part account for higher admission rates in these groups.

Second, the severity of the mental illness and/or the resultant disability may be greater in Black and minority ethnic groups. The Mini-Mental State Examination scores were lower among a community sample of African Caribbean elders compared with the general population, ${ }^{7}$ suggesting greater cognitive impairment, although the results may be influenced by cultural factors. A small community study, with a high refusal rate for participation, reported that African Caribbean elders compared with indigenous elders were more likely to have functional impairment. ${ }^{8}$ Also, convenience samples have reported higher depression scores in elderly Somalis. ${ }^{9}$ Collectively, despite methodological difficulties, these observations may partly explain higher admission rates in Black Caribbean and Black African service user groups.

Third, the potential risks to oneself or to others as a consequence of mental illness may be higher in some elderly Black and minority ethnic groups, but there are no data supporting this. Fourth, service components designed to enable patients to remain at home may not be culturally appropriate or sensitive and may lead to admission by default, which is consistent with institutional racism. ${ }^{3}$ Fifth, many Black and minority ethnic elders do not speak English and a significant number are illiterate even in their mother tongue. This will result in diagnostic difficulties ${ }^{10}$ and may lead to higher admission rates for assessment, but if this were true then it should apply equally to all Black and minority ethnic service users of all ages that lack fluency in English. Finally, there is an absence of matching vocabulary for psychiatric symptoms in some languages spoken by Black and minority ethnic elders ${ }^{10}$ and this too may lead to diagnostic difficulties resulting in admission for assessment.

\section{Length of hospital stay in elderly Black and minority ethnic service users}

Following admission, several factors may influence length of stay in hospital. First, assessment may be prolonged if the clinical team has difficulty in communicating with the patient due to language barrier. ${ }^{10}$ Second, the difficulties in securing professional interpreters may further contribute to delays in completing the assessment and formulating a treatment plan. Third, an absence of matching vocabulary for psychiatric symptoms in some languages spoken by Black and minority ethnic elders ${ }^{10}$ may lead to diagnostic difficulties resulting in longer length of admission. Fourth, lack of culturally appropriate and sensitive ward environment, meals and therapeutic activities may also lead to delays in recovery. Fifth, paucity of culturally appropriate and sensitive community services (e.g. day centres) may further prolong length of stay despite the patient being clinically fit for discharge. Finally, it is possible that elders from some Black and minority ethnic groups may genuinely respond more slowly to treatment; however, due to paucity of intervention studies in Black and minority ethnic groups and their general exclusion from intervention studies of indigenous elderly populations ${ }^{11}$ data supporting or refuting this point are absent. The last three factors may also point to institutional racism. ${ }^{3}$

\section{The way forward}

Black and minority ethnic elders have high general practice registration and high consultation rates, ${ }^{12}$ yet they were traditionally thought to be poorly represented in secondary care old age psychiatry services. ${ }^{10}$ Superficially, the findings from the 2007 Count Me In census suggest that this may not be true for some Black and minority ethnic groups. However, the 'standardised bed occupancy ratios' measured in that census need to be interpreted cautiously as they may be artifacts of increased length of stay rather than a genuine increase in uptake of in-patient services, and they only represent one component of a comprehensive old age psychiatry service. Data on length of stay, bed occupancy and completed consultant episodes by ethnicity and specialty (including old age psychiatry) are routinely collected for the hospital episode statistics and should be used to further examine this issue. There is a need to combine the data from the three Count Me In censuses to provide sufficiently large numbers of Black and minority ethnic elders to enable analysis on other indicators of possible institutional racism (including detention rates, seclusion rates, restraint rates, etc.). Additionally, for the combined 3-year data, there is also a need to compare and contrast the characteristics of Black and minority ethnic service users with and without increased standardised bed occupancy ratios. This may provide pointers to explain the differential bed occupancy across various Black and minority ethnic groups.

Although the Count Me In census provides invaluable information, it only refers to in-patients. Therefore, such additional re-analysis will not be sufficient. There is an urgent need to examine equity of access to different components of old age psychiatry services by elders from different Black and minority ethnic groups and to examine 
the differences in availability of mental health services between various Black and minority ethnic groups and indigenous White British service users. This can best be achieved using a pathways into care approach encompassing the following: prevalence of mental illness in the community; prevalence of mental illness in those who consult general practitioners; identification rates for mental illness in general practice; referral rates for mental illness to secondary care old age psychiatry services; identification rates for mental illness in secondary care old age psychiatry services; and identification of the specific treatment and care packages offered (including the service setting in which they will be delivered) by the secondary care old age psychiatry services. This will allow identification of the blocks and reasons for this across different service settings and allow development of intervention strategies to improve this. Unless, and until, such a comprehensive study with multiple centres is undertaken, speculation will continue about the reasons for either poor uptake or higher uptake of some components of old age psychiatry services by different Black and minority ethnic groups, and there will be no real change in service provision to meet their needs. Such work will also facilitate the main goals of the governmental document Delivering Race Equality in Mental Health Care, ${ }^{13}$ such as more appropriate and responsive services, community engagement and better information. It is reassuring that race equality will remain a priority in the next phase of mental health reform. ${ }^{5}$

\section{Declaration of interest}

None.

\section{References}

1 Shah AK, McKenzie K. Count me in even if I am old. J Royal Soc Med 2007; 100: 352-3.

2 Commission for Healthcare Audit and Inspection. Count Me In 2007. Results of the 2007 National Census of In-patientsi Mental Health and Learning Disability Services in England and Wales. Commission for Healthcare Audit and Inspection, 2007.

3 McKenzie K, Bhui K. Institutional racism in mental health care. Services have some way to go before they meet the challenges of a multicultural society. BMJ 2007 334: $649-50$.

4 Singh SP. Institutional racism in psychiatry: author's response. Psychiatr Bull 2007; 31: 370.

5 Appleby L. Services for ethnic minorities: a question of trust. Psychiatr Bull 2008; 32: 401-2.

$6 \mathrm{McCracken} \mathrm{CF}$, Boneham MA Copeland JR, Williams KE, Wilson K, Scott A, et al. Prevalence of dementia and depression among elderly people in Black and ethnic minorities. BrJ Psychiatr 1997; 171: 269-73.

7 Stewart R, Johnson J, Richards M, Brayne C, Mann A. The distribution of Mini-Mental State Examination scores in older UK African-

Caribbean population compared to MRC CFA study norms. Int/J Geriatr Psychiatr 2002; 17: $745-51$.

8 Richards M, Abas M, Carter J Osagie A, Levy R, Brayne C, et al. Social support and activities of daily living in older Afro-Caribbean and White UK residents. Age Ageing 1998; 27: 252-3.

9 Silveira E, Ebrahim S. Mental health and health status of elderly Bengalis and Somalis in London. Age Ageing 1991; 24: $474-80$

10 Shah AK. Can the recognition of clinical features of mental illness at clinical presentation in ethnic elders be improved? Intl J Geriatr Psychiatr 2007; 22: 277-82.

11 Shah AK, Doe P, Deverill K. Ethnic minority elders: are they neglected in published geraitric psychiatry literature? Int/ Psychoger 2008; 20 1041-5.

12 Lindesay J, Jagger C, Hibbert MJ, Peet SM, Moledina F. Knowledge, uptake and availability of health and social services among Asian Gujarati and White elders. Ethn Health 1997; 2: 59-69.

13 Department of Health. Delivering Race Equality in Mental Health Care. An Action Plan for Reform Inside and Outside Services and the Government's Response to the Independent Inquiry into the Death of David Bennett. Department of Health, 2005 (http://www.dh.gov. k/assetroot/04/10/07/75/ 04100775.pdf)

Ajit Shah Professor of Ageing, Ethnicity and Mental Health, University of Central Lancashire, Preston and Consultant Psychiatrist, West London Mental Health NHS Trust, London, John Connolly Unit, West Lonodn Mental Health NHS Trust, Uxbridge Road, Southall, MiddlesexUB13EU, email: ajit.shah@wlmht.nhs.uk 